\title{
Long-term health effects of persistent exposure to low-dose Ir192 gamma-rays
}

\author{
HONGBO LI $^{1 *}$, LIN WANG $^{2 *}$, ZUJUN JIANG $^{1}$, LI LI $^{1}$, ZHIFANG XIAO $^{1}$, ZENGHUI LIU $^{1}$, \\ SHUANG ZHANG $^{3}$, HUI JIN ${ }^{4}$, LEI SU ${ }^{4,5}$ and YANG XIAO ${ }^{1}$
}

${ }^{1}$ Department of Hematology, General Hospital of Guangzhou Military Command; ${ }^{2}$ Department of Emergency, The First Affiliated Hospital of Guangzhou University of Traditional Chinese Medicine, Guangzhou, Guangdong 510405;

${ }^{3}$ Department of ICU, Jiangmen Central Hospital, Jiangmen, Guangdong 529000; ${ }^{4}$ Department of ICU,

General Hospital of Guangzhou Military Command, Guangzhou, Guangdong 510010;

${ }^{5}$ Southern Medical University, Guangzhou, Guangdong 510515, P.R. China

Received May 14, 2015; Accepted June 27, 2016

DOI: $10.3892 / \mathrm{etm} .2016 .3682$

\begin{abstract}
The aim of the present study was to investigate the effect of persistent low-dose iridium-192 (Ir192) exposure on immunological function, chromosome aberration and the telomerase activity of bone marrow mononuclear cells (BMNCs), in order to increase clinical knowledge of the late effects of persistent low-dose Ir192 gamma-ray exposure. Patients $(\mathrm{n}=54)$ accidentally exposed to persistent low-dose Ir192 were included in this 10-year follow-up study. Clinical symptoms, peripheral blood, bone marrow, cellular and humoral immune status, chromosome aberrations and the telomerase activity of BMNCs were analyzed in this study. Exposure to low-dose Ir192 resulted in different degrees of clinical symptoms and significantly lowered complement $\mathrm{C} 3$ and $\mathrm{C} 4$ levels, $\mathrm{CD}^{+}, \mathrm{CD}^{+}{ }^{+}$and $\mathrm{CD} 8^{+} \mathrm{T}$ cell levels, the lymphocyte transformation rate and the percentage of natural killer (NK) cells. It also led to increases in peripheral blood and bone marrow abnormality rates, chromosome aberration rate and BMNC telomerase activity. Exposure to persistent low-dose Ir192 radiation resulted in different degrees of immune dysfunction, and abnormalities of blood cells and bone marrow, which recovered within 1-3 years. Chromosome aberrations were observed to take 5-10 years to recover. However, it would take $>10$ years for the telomerase activity of BMNCs to be reduced to
\end{abstract}

Correspondence to: Dr Lei Su, Department of ICU, General Hospital of Guangzhou Military Command, 111 Liuhua Road, Guangzhou, Guangdong 510000, P.R. China

E-mail: sulei_icu@163.com

Dr Yang Xiao, Department of Hematology, General Hospital of Guangzhou Military Command, 111 Liuhua Road, Guangzhou, Guangdong 510405, P.R. China

E-mail: jdxiao111@163.com

*Contributed equally

Key words: Ir192, telomerase, chromosome aberrations, cellular and humoral immune, follow up normal levels. A prolonged follow-up time is required in order to monitor clonal proliferative diseases such as leukemia.

\section{Introduction}

Iridium-192 (Ir192) is a radioactive isotope of iridium with a half-life of 73.83 days, which emits gamma radiation with a low level of linear energy transfer and a high level of penetration in the human body (1). Ir192 is frequently used as a gamma-ray source in industrial radiography to detect flaws in metal components (2). It is also used as a radiation source in radiotherapy; for example, it has been shown that Ir192 can reduce recurrent coronary restenosis following the initial percutaneous treatment of in-stent restenosis (3). However, exposure to high doses of Ir192 has a deleterious effect. It has been shown that the exposure of fingertips to 20-30 Sv Ir192 can cause progressive tissue deterioration and result in successive amputations of the fingers being necessary (2). An over-exposure to industrial radiography using Ir192 radionuclide may result in skin erythema, skin necrosis, progressive tissue deterioration and even malignant diseases such as myeloid leukemia, lymphoma and multiple myeloma $(4,5)$. It has been shown that acute exposure to large- or medium-dose radiation can seriously affect the blood and immune systems, leading to hematopoietic failure or hematopoietic tumors (6). However, the effect of low-dose ionizing radiation, particularly the effect of persistent low-dose irradiation on the human body remains unclear.

More than 70 people were unintentionally exposed to persistent low-dose Ir192 radiation in July 2002. The present study was conducted as a 10-year follow-up of those people, and was carried out to investigate the effect of persistent low-dose Ir192 exposure on immunological function, chromosome aberrations and the telomerase activity of bone marrow mononuclear cells (BMNCs). The effects of persistent low-dose Ir192 exposure on complement C3 and C4 levels, $\mathrm{CD}^{+}, \mathrm{CD}^{+}$ and $\mathrm{CD}^{+} \mathrm{T}$ cells, the lymphocyte transformation (LT) rate, and percentage of natural killer (NK) cells were determined. The abnormality rates of peripheral blood and bone marrow, the chromosome aberration rate, and bone marrow mononuclear cell telomerase activity were also analyzed. 


\section{Materials and methods}

Patients. In total, 54 people exposed to persistent low-dose Ir192 were included in this study. The inclusion criteria were as follows: i) Worked within a radius of 10 meters from the radiation source during accidental exposure (between May 9, 2002 and July 19, 2002); ii) diagnosed by the Chinese Institute of Radiation Medicine (Beijing, China) as receiving an exposure dose of 0.05-0.65 Grey (Gy). The exclusion criteria were as follows: i) Had been exposed to radiation before: ii) had cancer, tuberculosis, hepatitis or autoimmune disease; iii) had taken medicine in the previous 3 months. Among the 54 patients, there were 29 males and 25 females. The median age of the patients was 31.5 years (range, 20-42 years). The blood or bone marrow samples of the control group were obtained from 20 healthy volunteer bone marrow donors. This study was approved by the Institutional Review Boards (IRBs) of the General Hospital of Guangzhou Military Command (Guangzhou, China). Written informed consent was obtained from all patients in accordance with the IRB regulations and the Declaration of Helsinki.

General information. Clinical symptoms, abnormality rates of peripheral blood and bone marrow, immunoglobulin and complement (IgA, IgG, IgM, C3 and C4) levels, T cell subsets $\left(\mathrm{CD}^{+}, \mathrm{CD}^{+}\right.$and $\left.\mathrm{CD}^{+}\right)$, the $\mathrm{LT}$ rate, percentage of NK cells, chromosome aberration rate and BMNC telomerase activity were recorded at different time points (1 month, and 1,3,5 and 10 years after exposure).

Blood tests. An HMX LH500 blood cell analyzer (Beckman Coulter, Inc., Brea, CA, USA) was used to analyze peripheral blood samples. Bone marrow was taken by posterior superior iliac spine bone marrow aspiration, smeared, Wright-Giemsa stained and observed under an inverted microscope. Abnormal blood was defined by a white blood cell (WBC) count of $>10.0 \times 10^{9} / 1$ or $<4.0 \times 10^{9} / 1$, hemoglobin $(\mathrm{Hb})$ level of $<120 \mathrm{~g} / 1$ (male) or $<110 \mathrm{~g} / 1$ (female), or platelet count of $<10010^{9} / 1$. Bone marrow suppression, active bone marrow proliferation, and hyperactive bone marrow proliferation were defined as myelodysplasia. Morphological abnormality was defined as $>2 \%$ of nucleated cells showing a morphological abnormality.

Tests of $T$ cell subset. Cells were incubated with fluorescence-labeled monoclonal antibodies and were observed under a fluorescence microscope to calculate the percentage of positive cells. Briefly, BD Pharm Lyse lysing buffer was applied to human whole blood red blood cells (BD Biosciences, San Jose, CA, USA) with a monoclonal antibody mixture and gently vortexed. Monoclonal antibodies include anti-CD3 antibody (cat. no. ab16669; 1:1,000 dilution), anti-CD4 antibody (cat. no. ab133616; 1:100 dilution), anti-CD8 antibody (cat. no. ab17147; 1:100 dilution), anti-CD57 antibody (cat. no. ab25629; 1:100 dilution) (all purchased Abcam, Cambridge, MA, USA). Following incubation for $15 \mathrm{~min}$ at room temperature, the mixture was centrifuged at $200 \mathrm{x} \mathrm{g}$ for $5 \mathrm{~min}$ and the supernatant was aspirated. It was added to phosphate buffered saline-fetal bovine serum (PBS-FBS; containing $1 \%$ heat-inactivated fetal bovine serum; Gibco; Thermo Fisher Scientific, Waltham, MA, USA; and 0.1\% sodium azide), the pellet was re-suspended with PBS-FBS after centrifugation at $200 \mathrm{x}$ g for flow cytometric analysis. The absolute cell count and the marker percentage were calculated using FACSCalibur (BD Biosciences).

Chromosome aberration assay. Peripheral blood ( $3 \mathrm{ml})$ was collected from each patient and incubated at $37^{\circ} \mathrm{C}$ for $2 \mathrm{~h}$ to allow it naturally stratify. Cells from the interfacial layer $(0.1 \mathrm{ml})$ were cultured in RPMI-1640 (Thermo Fisher Scientific, Inc.) containing 15\% fetal bovine serum (Sigma-Aldrich, St. Louis, MO, USA) in a $37^{\circ} \mathrm{C}$ incubator. Colchicine was added to the cells at a concentration of $0.05 \mu \mathrm{g} / \mathrm{ml} 24 \mathrm{~h}$ after incubation. Cells were collected $48 \mathrm{~h}$ after incubation, stained with Giemsa, and observed under an inverted microscope. A total of 200 metaphase cells were counted and chromosome aberrations were analyzed.

Automatic karyotype analysis (G-binding). The bone marrow culture was applied for the preparation of conventional chromosomes. Based on G-banding technology, chromosomal karyotypes analysis was developed and 20 mitoses were counted. Abnormal karyotypes were determined according to the International System for Human Cytogenetic Nomenclature 1995 (ISCN 1995). An AMMS-1 karyotype analyzer (Q500; Leica Microsystems GbmH, Wetzlar, Germany) was used in this experiment.

Measurement of BMNC telomerase activity. A telomeric repeat amplification protocol-enzyme linked immunosorbent assay (TRAP-ELISA; cat. no. CB42542175; EMD Millipore, Billerica, MA, USA) was used in this experiment. Briefly, BMNCs were isolated by Ficoll density gradient centrifugation (room temperature, $400 \mathrm{x} \mathrm{g}, 20 \mathrm{~min}$ ). TRAP-ELISA was performed according to the manufacturer's protocol.

Statistical analysis. SPSS 11.0 software (SPSS Inc., Chicago, IL, USA) was used to perform the statistical analysis. All data are expressed as the mean \pm standard deviation. The results were analyzed using Student's t-test or one-way analysis of variance followed by Student-Newman-Keuls post-hoc test. In all tests, $\mathrm{P}<0.05$ was considered to indicate a statistically significant difference.

\section{Results}

Follow-up of clinical symptoms. The results shown in Fig. 1 show that 1 month after exposure, 90.7\% patients exhibited clinical symptoms of various degrees, including dizziness, fatigue, memory loss or insomnia, bleeding gums, mouth ulcers, abdominal pain, diarrhea, heavy menstrual bleeding, palpitations or chest tightness, and alopecia. These symptoms were only observed in $7 / 54$ patients (13.0\%), 3/42 patients (7.1\%) and $3 / 31$ patients $(9.7 \%)$ in the follow-up checks at years 1,5 and 10 after exposure. Among the 3 patients who exhibited prolonged symptoms, 1 patient was exposed to a large dose ( $>1.5 \mathrm{~Gy})$. No aplastic anemia, bone marrow failure diseases or leukemia were found in this 10 -year follow-up study.

Parameters in blood and bone marrow. The proportion of patients with an abnormal WBC count was $44.4 \%$ (24/54) 


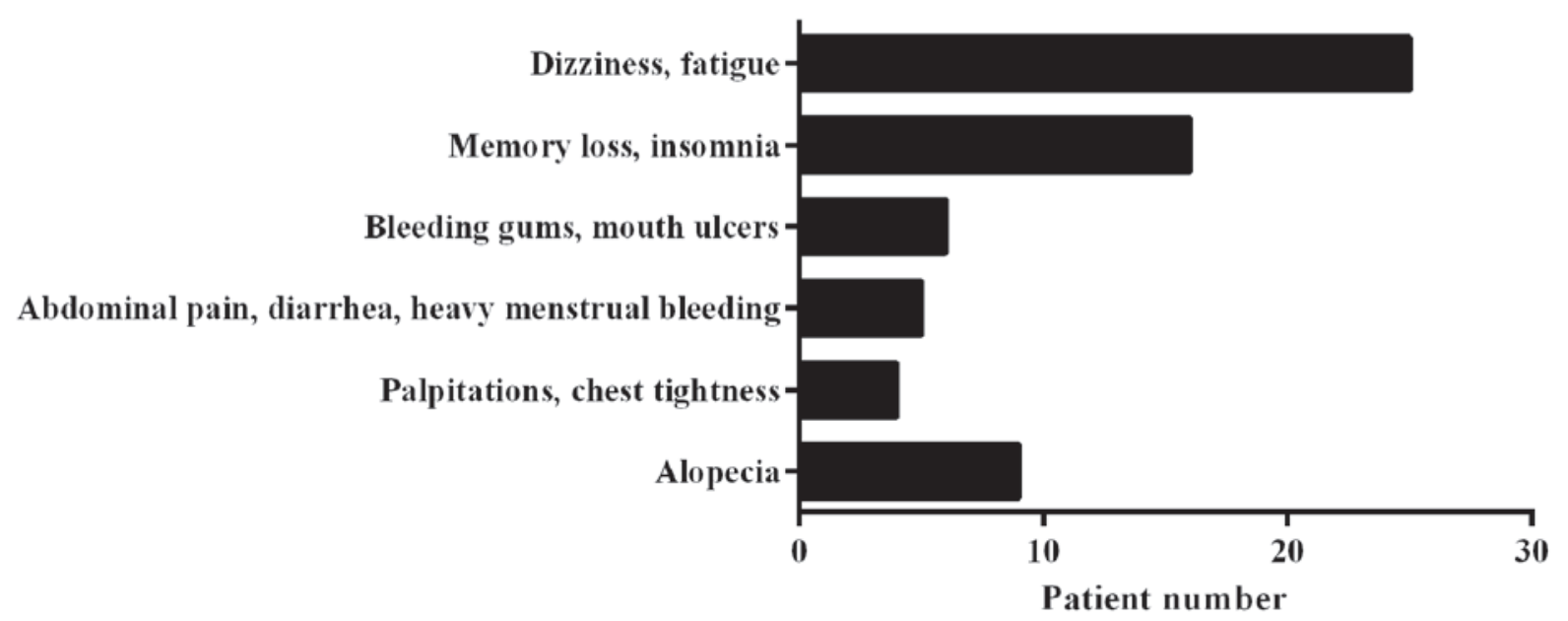

Figure 1. Clinical symptoms of Ir192 exposure. Various clinical symptoms shown by patients 1 month after Ir192 exposure. Ir192, iridium-192.

1 month after exposure, and this decreased to $24.1 \%(13 / 54)$ 1 year post exposure, $18.0 \%(9 / 50) 3$ years post exposure, $16.7 \%$ (7/42) 5 years post exposure and $9.7 \%(3 / 31) 10$ years post exposure. Morphological abnormalities were observed in bone marrow granulocytes, erythrocytes and megakaryocytes. The morphological abnormality rate was $90.7 \%$ at 1 month after exposure, and this decreased to $18.5 \% 1$ year post exposure, $12.0 \% 3$ years post exposure, $9.5 \% 5$ years post exposure and $12.9 \% 10$ years post exposure (Table I). Erythrocyte morphological abnormalities included small red blood cells, giant red blood cells and immature red blood cells (Fig. 2A). Megakaryocyte morphological abnormalities were mainly exhibited as increased number of small megakaryocytes and original megakaryocytes. Granulocyte morphological abnormalities that were observed were mainly cell swelling, reduced number of cytoplasmic granules, karyopyknosis, spinous changes (Fig. 2B), vacuolar degeneration (Fig. 2C), toxic granulation and increasing number of myeloblasts and promyelocytes (Fig. 2D).

Immune function parameters. Complement $\mathrm{C} 3$ and $\mathrm{C} 4$ levels were significantly decreased 1 month after exposure when compared with those of normal controls $(\mathrm{P}<0.01)$, and recovered to a normal level 1 year after exposure. No significant changes were found in $\operatorname{IgA}, \operatorname{IgG}$ or IgM levels (Table II). At 1 month after exposure, the $\mathrm{CD}^{+}, \mathrm{CD}^{+}, \mathrm{CD} 8^{+}$and $\mathrm{CD} 4^{+} / \mathrm{CD}^{+} \mathrm{T}$ cell levels, LT rate and percentage of NK cells were significantly lower than those of the controls $(\mathrm{P}<0.01)$, and these values had recovered to normal levels by 3 years after exposure (Table III).

Chromosome aberrations. The chromosome aberration rates of the patients were determined at 1 month, and at $1,3,5$ and 10 years after exposure. The results demonstrated that at 1 month after exposure, the rate of dicentric and centric-ring aberrations was $4.76 \pm 0.37 \%$, and the total rate of chromosome aberrations was $9.62 \pm 0.52 \%$. The rate of dicentric and centric-ring aberrations was decreased to $0.96 \pm 0.15 \%$ at 1 year after exposure (Table IV). The karyotypes of 4 patients at 1 month after exposure are shown in Fig. 3. The chromosome karyotype of one of these patients exhibited three anomalies. These anomalies were Y chromosome deletions (Fig. 3B), Another patient exhibited $\mathrm{X}$ chromosome, and chromosome $4,5,7,8,10,12,13$ deletions, and chromosomes 11 and 14 had a derivative chromosome (Fig. 3D). The remaining two individuals appeared to have normal karyotypes (Fig. 3A and C).

Changes in the telomerase activity of BMNCs. The telomerase activity of BMNCs in the experimental group $(\mathrm{n}=54)$ was $0.47 \pm 0.04$ at 1 month after exposure, which was significantly higher than that of the controls. At 5 and 10 years after exposure, the telomerase activity of BMNCs in the experimental group was $0.32 \pm 0.03$ and $0.18 \pm 0.02$, respectively, and remained significantly higher than that of the controls (Fig. 4).

\section{Discussion}

Although the clinical symptoms of persistent low-dose radiation exposure vary due to differences in doses and the duration of exposure, the biological effects are mainly excitatory effects and adaptation effects. The irradiation accident in this study lasted 70 days; however, it was not possible to accurately define the exposure time and dose. According to the analysis of lymphocyte chromosome aberrations, the Chinese Institute of Radiation Medicine diagnosed that the exposure dose was 0.05-0.65 Gy. The majority of the patients' clinical symptoms had disappeared by 1 year after exposure. The reason why there were 3 patients who continued to exhibit clinical symptoms might be that these 3 patients were exposed to a large dose (>1.5 Gy). The hematopoietic system is highly sensitive to ionizing radiation. Large or medium-dose acute exposure can seriously damage the body's hematopoietic function, leading to hematopoietic failure or hematopoietic tumors (7). However, the impact of low-dose ionizing radiation on the hematopoietic system has not been fully evaluated. It has been observed that WBC counts exhibit a significant reduction following gamma-radiation $(8,9)$. Researchers showed that in the Chernobyl accident, changes occurred in red blood cells, $\mathrm{Hb}$ levels, platelet quality and quantity in people exposed to $<1 \mathrm{~Gy}$ radiation. They also found that the incidence of thyroid 
Table I. Parameters of the blood and bone marrow of patients following Ir192 exposure.

\begin{tabular}{|c|c|c|c|c|c|c|}
\hline \multirow[b]{2}{*}{ Time point } & \multirow[b]{2}{*}{ No. of patients } & \multicolumn{3}{|c|}{ Abnormal blood results, n (\%) } & \multicolumn{2}{|c|}{ Abnormal bone marrow, n (\%) } \\
\hline & & WBC & $\mathrm{Hb}$ & PLT & Morphology & Hyperplasia \\
\hline 1 month & 54 & $24(44.4)$ & $7(13.0)$ & $7(13.0)$ & 49 (90.7) & $3(5.6)$ \\
\hline 1 year & 54 & $13(24.1)$ & $5(9.2)$ & $3(5.6)$ & $10(18.5)$ & $3(5.6)$ \\
\hline 3 years & 50 & $9(18.0)$ & $4(8.0)$ & $2(4.0)$ & $6(12.0)$ & $3(6.0)$ \\
\hline 5 years & 42 & $7(16.7)$ & $2(4.8)$ & $2(4.8)$ & $4(9.5)$ & $3(7.1)$ \\
\hline 10 years & 31 & $3(9.6)$ & $2(6.5)$ & $0(0)$ & $4(12.9)$ & $3(9.7)$ \\
\hline
\end{tabular}

WBC, white blood cell; Hb, hemoglobin; PLT, platelet; Ir192, iridium-192.

A

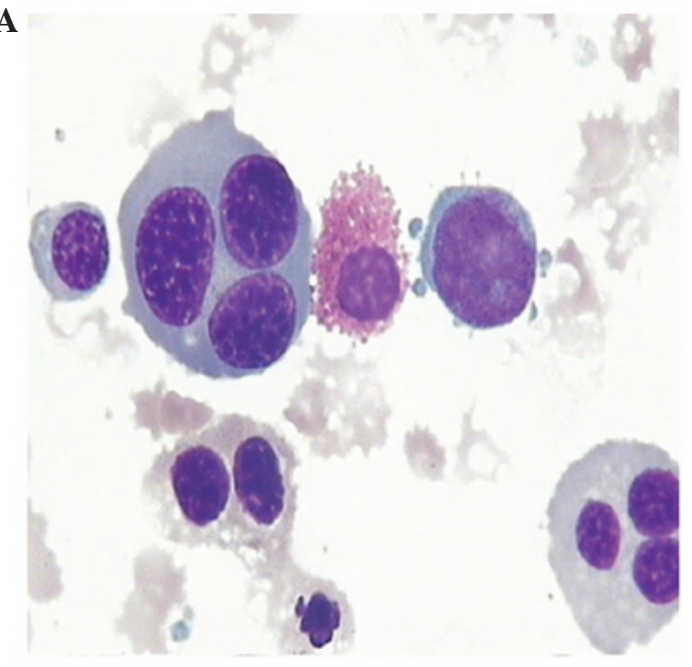

$\mathrm{C}$

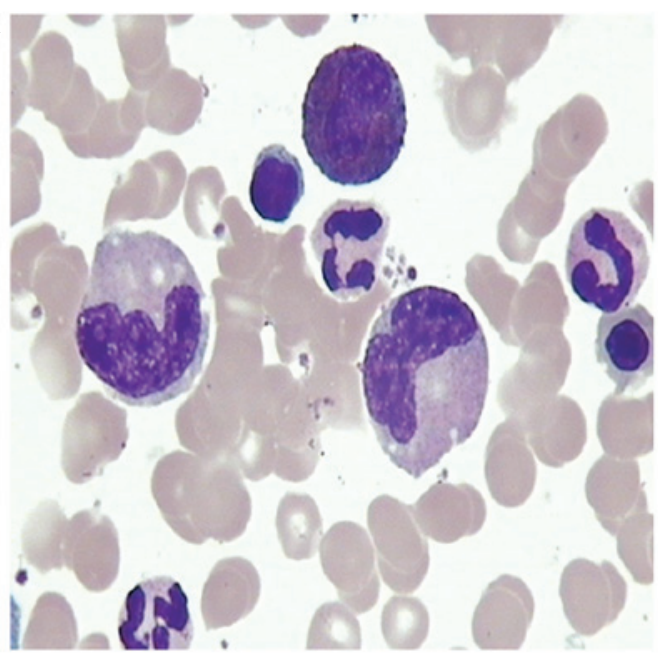

B

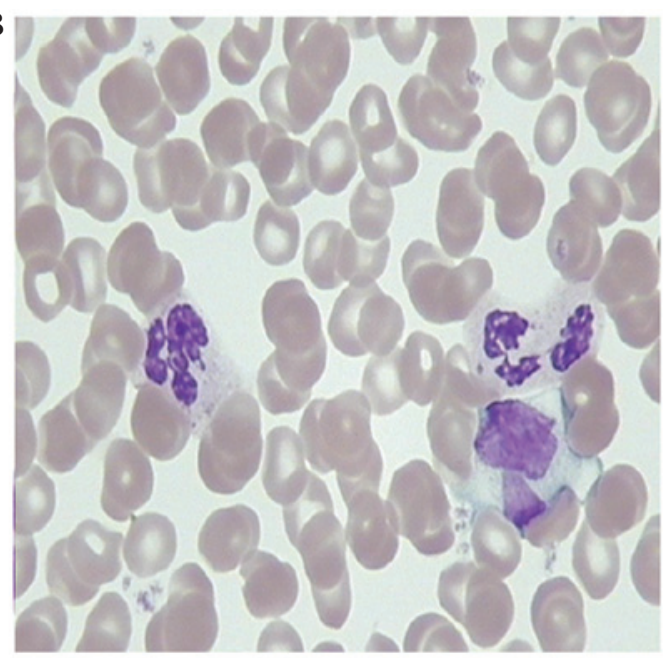

D

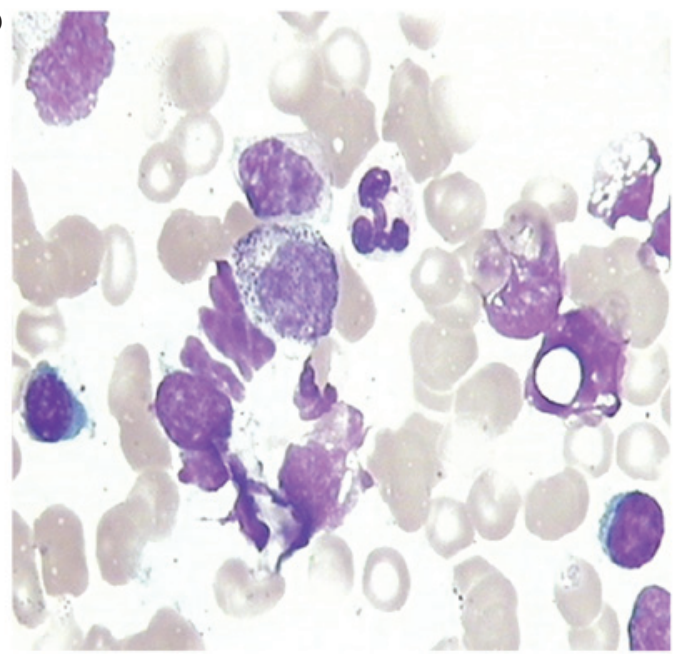

Figure 2. Bone marrow aspirate smears of patients exposed to iridium-192. Representative images of (A) tri-nucleated red blood cells, (B) spinous process degenerative changes, (C) reduced cytoplasmic granules and vacuolar degeneration and (D) increased degenerated cells. Wright-Giemsa staining. Magnification, $\mathrm{x} 400$.

cancer and acute leukemia was significantly increased accompanied by an increase in P53 gene mutation among those who were irradiated during their childhood (10-12), indicating that age, dose, frequency, time and different stages after exposure could significantly affect the quality and quantity of blood cells and the incidence of tumors. The results of the present study indicated that persistent 0.05-0.65 Gy Ir192 did not cause irreversible inhibition or damage of the hematopoietic system in the affected population, and it may be speculated that the human hematopoietic system is effectively able to compensate for the damage caused by persistent $0.05-0.65 \mathrm{~Gy}$ Ir192 exposure.

The body's immune system is also highly sensitive to ionizing radiation. Low-dose long-term radiation has been 
Table II. Immunoglobulin and complement changes of patients following Ir192 exposure (g/l).

\begin{tabular}{|c|c|c|c|c|c|}
\hline Group & No. of patients & $\operatorname{Ig} \mathrm{A}$ & $\operatorname{IgM}$ & C3 & $\mathrm{C} 4$ \\
\hline Control & 20 & $1.88 \pm 0.35$ & $10.37 \pm 2.33$ & $0.95 \pm 0.18$ & $0.18 \pm 0.08$ \\
\hline \multicolumn{6}{|c|}{ Experimental groups } \\
\hline 1 month & 54 & $1.96 \pm 0.34$ & $9.59 \pm 1.43$ & $0.62 \pm 0.14^{\mathrm{a}}$ & $0.05 \pm 0.03^{\mathrm{a}}$ \\
\hline 1 year & 54 & $2.14 \pm 0.32$ & $10.39 \pm 2.04$ & $0.94 \pm 0.33$ & $0.16 \pm 0.01$ \\
\hline 3 years & 50 & $1.94 \pm 0.42$ & $10.20 \pm 1.62$ & $0.87 \pm 0.14$ & $0.18 \pm 0.03$ \\
\hline 5 years & 42 & $1.93 \pm 0.35$ & $9.92 \pm 1.33$ & $1.04 \pm 0.47$ & $0.21 \pm 0.03$ \\
\hline 10 years & 31 & $1.91 \pm 0.29$ & $10.20 \pm 2.07$ & $1.01 \pm 0.29$ & $0.24 \pm 0.04$ \\
\hline
\end{tabular}

${ }^{a} \mathrm{P}<0.01$ vs. the control group. IgA, immunoglobulin A; IgM, immunoglobulin M; C3, complement component 3; C4, complement component 4; Ir 192, iridium- 192.

Table III. Changes in the T cell subsets, LT rate and percentage of NK cells of patients following Ir192 exposure.

\begin{tabular}{|c|c|c|c|c|c|c|c|}
\hline Groups & No. of patients & $\mathrm{CD}^{+}(\%)$ & $\mathrm{CD}^{+}(\%)$ & $\mathrm{CD}^{+}(\%)$ & $\mathrm{CD}^{+} / \mathrm{CD}^{+}$ & $\mathrm{LT}$ rate $(\%)$ & NK cells $(\%)$ \\
\hline Control & 20 & $74.3 \pm 7.6$ & $49.9 \pm 4.2$ & $29.5 \pm 2.6$ & $1.69 \pm 0.3$ & $84.5 \pm 5.1$ & $13.7 \pm 0.1$ \\
\hline \multicolumn{8}{|c|}{ Experimental groups } \\
\hline 1 month & 54 & $49.1 \pm 5.1^{\mathrm{a}}$ & $42.0 \pm 4.7^{\mathrm{a}}$ & $20.8 \pm 2.7^{\mathrm{a}}$ & $1.97 \pm 0.1^{\mathrm{a}}$ & $48.6 \pm 2.5^{\mathrm{a}}$ & $8.43 \pm 0.2^{\mathrm{a}}$ \\
\hline 1 year & 54 & $52.3 \pm 4.8^{\mathrm{a}}$ & $43.1 \pm 4.1^{\mathrm{a}}$ & $22.1 \pm 3.8^{\mathrm{a}}$ & $2.01 \pm 0.2^{\mathrm{a}}$ & $60.5 \pm 4.1^{\mathrm{a}}$ & $8.85 \pm 1.6^{\mathrm{a}}$ \\
\hline 3 years & 50 & $70.3 \pm 4.2$ & $48.5 \pm 2.9$ & $29.4 \pm 3.5$ & $1.77 \pm 0.2$ & $80.5 \pm 3.1$ & $12.7 \pm 0.3$ \\
\hline 5 years & 42 & $71.1 \pm 4.0$ & $49.4 \pm 2.3$ & $28.3 \pm 2.5$ & $1.80 \pm 0.3$ & $86.9 \pm 3.8$ & $12.1 \pm 0.2$ \\
\hline 10 years & 31 & $70.9 \pm 3.0$ & $50.0 \pm 3.4$ & $30.1 \pm 2.6$ & $1.73 \pm 0.4$ & $88.3 \pm 5.7$ & $13.1 \pm 0.4$ \\
\hline
\end{tabular}

${ }^{a} \mathrm{P}<0.01$, experimental group vs. control group. CD, cluster of differentiation; LT, lymphocyte transformation; NK, natural killer; Ir192, iridium-192.

Table IV. Chromosomal aberrations of patients following Ir192 exposure.

\begin{tabular}{lrrrrr}
\hline Time point & Number & C+D $(\%)$ & AA $(\%)$ & SA $(\%)$ & Chromosome aberration $(\%)$ \\
\hline 1 month & 9,400 & $4.82 \pm 0.65$ & $3.06 \pm 0.23$ & $1.05 \pm 0.05$ & $9.62 \pm 0.52$ \\
1 year & 10,400 & $0.96 \pm 0.15$ & $0.81 \pm 0.13$ & $0.19 \pm 0.01$ & $1.83 \pm 0.39$ \\
3 years & 9,200 & $0.42 \pm 0.05$ & $0.58 \pm 0.15$ & $0.13 \pm 0.02$ & $1.36 \pm 0.15$ \\
5 years & 8,400 & $0.20 \pm 0.05$ & $0.47 \pm 0.32$ & $0.09 \pm 0.01$ & $0.82 \pm 0.24$ \\
10 years & 6,200 & $0.05 \pm 0.01$ & $0.40 \pm 0.08$ & $0.02 \pm 0.00$ & $0.47 \pm 0.15$ \\
\hline
\end{tabular}

C+D, dicentric and centric-ring aberration; AA, acentric aberration; SA, stable aberration; Ir192, iridium-192.

shown to enhance immune function (13), whereas high-dose exposure may inhibit immune function $(13,14)$. The results of the present study indicated that humoral immunity can be restored in a short time period, and lymphocytes are extremely sensitive to radiation and their self-healing rate is very slow. It has been reported that immune disorders may be sustained for more than 30 years; the $\mathrm{IgG}, \mathrm{CD}^{+}, \mathrm{CD}^{+}$and $\mathrm{CD}^{+} 6^{+}$levels of individuals involved in the clean-up of the Chernobyl nuclear leak were significantly lowered and thyroid disease was identified in 59 cases in 385 participants (10). However, immune stimulatory and excitatory effects of low-dose irradiation were not observed in the present study, which may be associated with the special nature of the observed population.

The chromosomes of peripheral blood lymphocytes may be damaged by small doses of radiation leading to chromosomal aberrations. Thus, the estimation of a radiation dose by analyzing chromosome aberrations in peripheral blood lymphocytes has been widely recognized as a diagnostic method (15-17). In the present study, the rate of dicentric and centric-ring aberrations was $4.82 \pm 0.65 \%$ at 1 month after exposure, and was decreased by $80 \%$ at 1 year after exposure. No aberrations were found 10 years after exposure. 
A

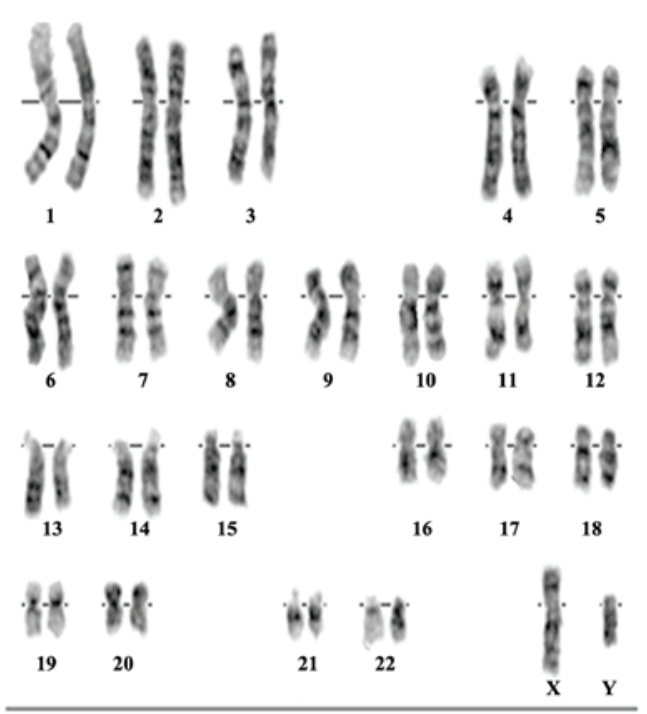

C

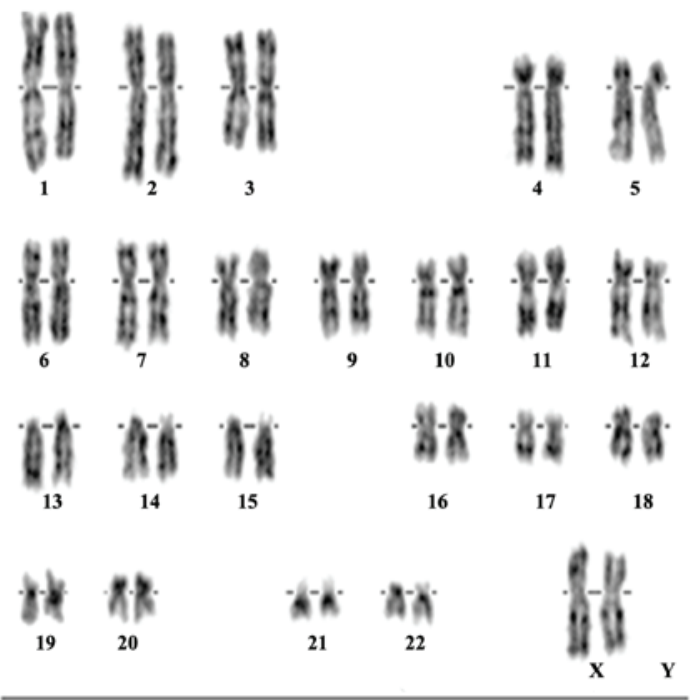

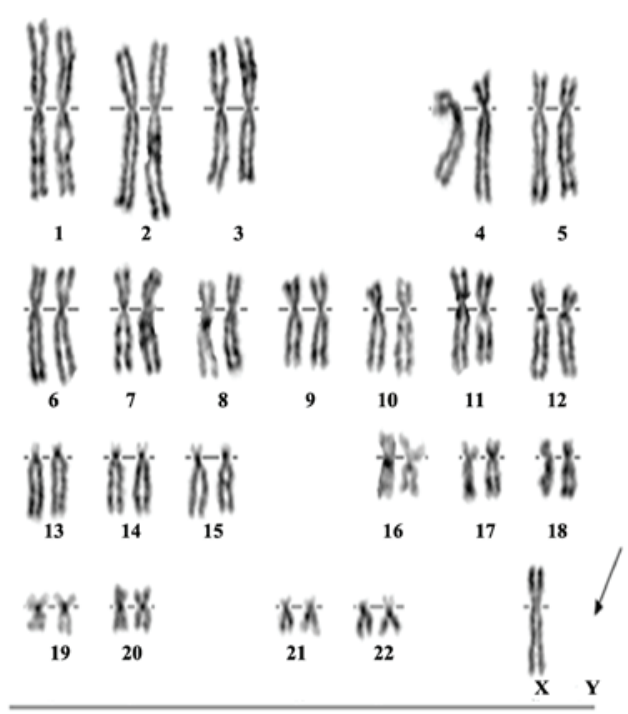

D
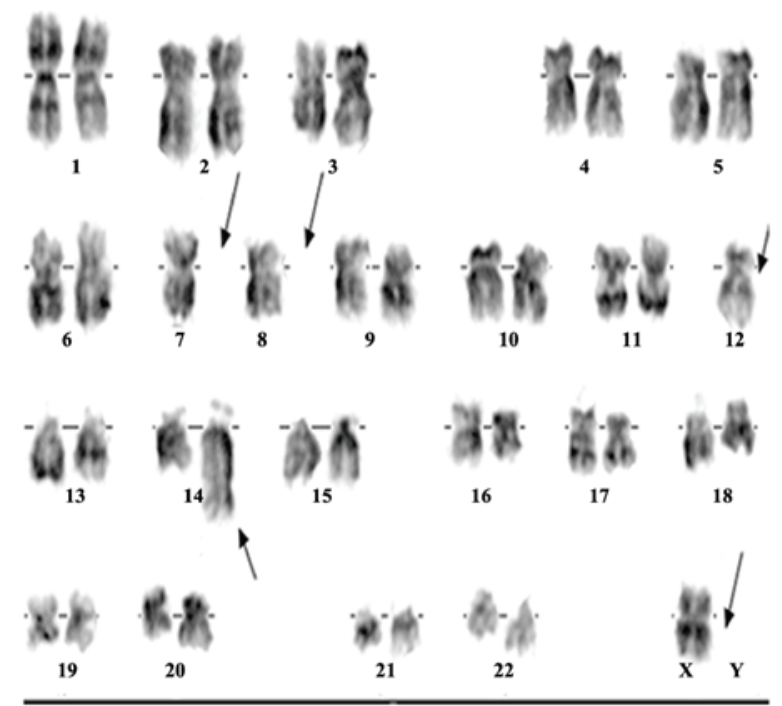

Figure 3. Automatic karyotype analysis of chromosome aberrations. Four representative images of chromosome aberrations from 4 patients at 1 month after iridium-192 exposure. (A) Male patient, 32 years old, 46, XY. (B) Male patient, 23 years old, 45, X, -Y. (C) Female patient, 42 years old, 46, XX. (D) Female patient, 25 years old, $45, \mathrm{X},-\mathrm{X}$.

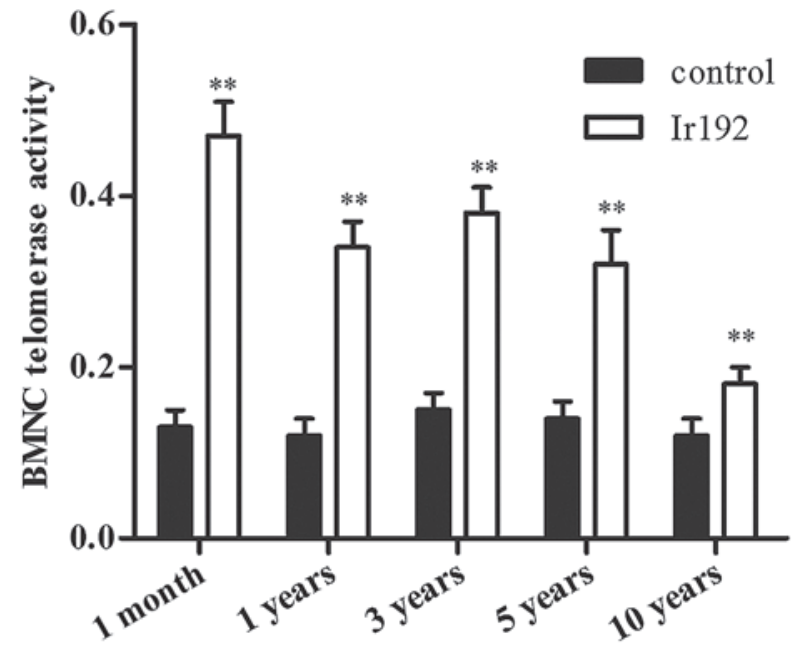

Figure 4. BMNC telomerase activity of patients exposed to Ir192 and normal controls measured at various time points. ${ }^{* *} \mathrm{P}<0.01$ versus the control. BMNC, bone marrow mononuclear cell; IR192, iridium-192.
It has previously been shown that ionizing radiation can cause DNA damage, and ultimately lead to nucleus swelling, shrinkage, dissolution and then apoptosis $(18,19)$. However, DNA damage can activate telomerase activity, that is small doses of radiation are able to induce the expression of telomerase $(20,21)$. Highly expressed telomerase may be able to lengthen telomeres to repair radiation-damaged cellular DNA, and has the potential to induce malignant hematopoietic cell clones (22-24). The telomerase activity of BMNCs in the experimental group was significantly higher than that of controls even at 5 or 10 years after exposure, suggesting that after receiving the same dose of radiation, the recovery of BMNC telomerase activity takes more time than the recovery of hematopoietic and immune systems. Although no new aberrations or leukemia were found in the patients in the present study at 10 years after exposure, a longer follow-up time is required to conclude whether sustained high expression of telomerase is a risk factor of cancers or not. 
In the present study, doctor billing records were used to determine when follow-ups occurred, but no information about the intents for these visits was available. Therefore, some visits may have been routine appointments, and some patients may have scheduled an appointment but not have agreed to follow-up.

The results of the present study indicate that exposure to persistent low-dose Ir192 radiation resulted in different degrees of immune dysfunction, abnormalities of blood cells, abnormalities of bone marrow, chromosome aberrations, and changes in the telomerase activity of BMNCs. Immune dysfunction, abnormalities of blood cells and abnormalities of bone marrow were recovered within 1-3 years in the majority of cases. Chromosome aberrations took 5-10 years for recovery. However, it appears to take $>10$ years for the telomerase activity of BMNCs to recover. A longer follow-up time is required in order to monitor the development of clonal proliferative diseases such as leukemia.

\section{Acknowledgements}

This study was supported by funds from the PLA Medical Science and Technology Research 12th Five-Year Plan key project funded projects (BWS11J071), the Natural Science Foundation of Guangdong Province (05000138), and the Guangzhou Health Collaborative Innovation Major Projects (201400000003-1 and 201400000003-4).

\section{References}

1. Milacic S and Simic J: Case report: Iridium 192 - health effects during 20 years after irradiation. Kobe J Med Sci 54: E108-E113, 2008.

2. Jalil A and Molla MA: Accidental overexposure to 192Ir source in industrial radiography: A follow-up study. Health Phys 62: 74-76, 1992.

3. Moses JW, Moussa I, Leon MB, Teirstein PS, Fish RD, Ellis SG Nawas D, Kluck B, Giorgianni JA, Donohoe D and Kuntz RE: Effect of catheter-based iridium-192 gamma brachytherapy on the added risk of restenosis from diabetes mellitus after intervention for in-stent restenosis (subanalysis of the GAMMA I Randomized Trial). Am J Cardiol 90: 243-247, 2002.

4. Inskip PD, Kleinerman RA, Stovall M, Cookfair DL, Hadjimichael O, Moloney WC, Monson RR, Thompson WD, Wactawski-Wende J and Wagoner JK: Leukemia, lymphoma and multiple myeloma after pelvic radiotherapy for benign disease. Radiat Res 135: 108-124, 1993.

5. Butenko ZA, Smirnova IA, Zak KP, Kishinskaja EG and Janok EA: Leukemia-associated gene rearrangements in blood mononuclears of subjects in long terms after radiation exposure. J Exp Clin Cancer Res 19: 57-59, 2000.

6. Samarth RM: Protection against radiation induced hematopoietic damage in bone marrow of Swiss albino mice by Mentha piperita (Linn). J Radiat Res 48: 523-528, 2007.

7. Li Q, Sun H, Xiao F, Wang X, Yang Y, Liu Y, Zhang Q, Wu C Wang $\mathrm{H}$ and Wang LS: Protection against radiation-induced hematopoietic damage in bone marrow by hepatocyte growth factor gene transfer. Int J Radiat Biol 90: 36-44, 2014.
8. Maks CJ, Wan XS, Ware JH, Romero-Weaver AL, Sanzari JK, Wilson JM, Rightnar S, Wroe AJ, Koss P, Gridley DS, et al: Analysis of white blood cell counts in mice after gamma-or proton-radiation exposure. Radiat Res 176: 170-176, 2011.

9. Sanzari JK, Wan XS, Krigsfeld GS, Wroe AJ, Gridley DS and Kennedy AR: The effects of gamma and proton radiation exposure on hematopoietic cell counts in the ferret model. Gravit Space Res 1: 79-94, 2013

10. Kurjane N, Bruvere R, Shitova O, Romanova T, Jaunalksne I, Kirschfink M and Sochnevs A: Analysis of the immune status in Latvian Chernobyl clean-up workers with nononcological thyroid diseases. Scand J Immunol 54: 528-533, 2001.

11. Ivanov VK, Tsyb AF, Gorsky AI, Maksyutov MA, Rastopchin EM, Konogorov AP, Korelo AM, Biryukov AP and Matyash VA: Leukaemia and thyroid cancer in emergency workers of the Chernobyl accident: Estimation of radiation risks (1986-1995). Radiat Environ Biophys 36: 9-16, 1997.

12. Nikiforov YE, Nikiforova MN, Gnepp DR and Fagin JA: Prevalence of mutations of ras and p53 in benign and malignant thyroid tumors from children exposed to radiation after the Chernobyl nuclear accident. Oncogene 13: 687-693, 1996.

13. Bogdándi EN, Balogh A, Felgyinszki N, Szatmári T, Persa E, Hildebrandt G, Sáfrány G and Lumniczky K: Effects of low-dose radiation on the immune system of mice after total-body irradiation. Radiat Res 174: 480-489, 2010.

14. Cui YF, Ding YQ, Xu H, Liu XL, Jin W, Mao JP and Mao BZ: The effects of acute large dose of gamma-irradiation on immune function of mice. Xi Bao Yu Fen Zi Mian Yi Xue Za Zhi 20: 675-677, 2004 (In Chinese).

15. Agrawala PK, Adhikari JS and Chaudhury NK: Lymphocyte chromosomal aberration assay in radiation biodosimetry. J Pharm Bioallied Sci 2: 197-201, 2010.

16. Liu Q, Cao J, Wang ZQ, Bai YS, Lü YM, Huang QL, Zhao WZ, Li J, Jiang LP, Tang WS, et al: Dose estimation by chromosome aberration analysis and micronucleus assays in victims accidentally exposed to (60)Co radiation. Br J Radiol 82: 1027-1032, 2009.

17. Rozgaj R, Kasuba V and Simić D: The frequency of dicentrics and acentrics and the incidence of rogue cells in radiation workers. Mutagenesis 17: 135-139, 2002.

18. Watters D: Molecular mechanisms of ionizing radiation-induced apoptosis. Immunol Cell Biol 77: 263-271, 1999.

19. Lee JH, Kim SY, Kil IS and Park JW: Regulation of ionizing radiation-induced apoptosis by mitochondrial $\mathrm{NADP}^{+}$-dependent isocitrate dehydrogenase. J Biol Chem 282: 13385-13394, 2007.

20. Neuhof D, Ruess A, Wenz F and Weber KJ: Induction of telomerase activity by irradiation in human lymphoblasts. Radiat Res 155: 693-697, 2001.

21. Wang X, Liu Y, Chow LS, Wong SC, Tsao GS, Kwong DL, Sham JS and Nicholls JM: Regulation of telomerase activity by gamma-radiation in nasopharyngeal carcinoma cells. Anticancer Res 20: 433-437, 2000.

22. Akiyama M, Ozaki K, Kawano T, Yamada O, Kawauchi K, Ida H and Yamada $\mathrm{H}$ : Telomerase activation as a repair response to radiation-induced DNA damage in Y79 retinoblastoma cells. Cancer Lett 340: 82-87, 2013

23. Sun J, Huang H and Zhu YY: Study on the expression of tankyrase in malignant hematopoietic cells and its relation with telomerase activity. Zhongguo Shi Yan Xue Ye Xue Za Zhi 12: 11-15, 2004 (In Chinese).

24. Wang L, Xiao $\mathrm{H}$, Zhang $\mathrm{X}$, Wang $\mathrm{C}$ and Huang $\mathrm{H}$ : The role of telomeres and telomerase in hematologic malignancies and hematopoietic stem cell transplantation. J Hematol Oncol 7: 61, 2014. 